\title{
Diphenyl diselenide derivatives inhibit microbial biofilm formation involved in wound infection
}

\author{
Luca Sancineto ${ }^{1}$, Miranda Piccioni ${ }^{1}$, Stefania De Marco ${ }^{1}$, Rita Pagiotti ${ }^{1}$, Vanessa Nascimento ${ }^{2}$, Antonio Luiz Braga ${ }^{2}$, \\ Claudio Santi ${ }^{1}$ and Donatella Pietrella ${ }^{1 *}$
}

\begin{abstract}
Background: Organoselenium compounds have antimicrobial activity against some bacteria and fungi; furthermore, the antioxidant activity of diselenides has been demonstrated. The aim of the present work was to examine the in vitro minimal inhibitory concentration of a panel of differently substituted diselenides and their effectiveness in inhibiting biofilm formation and dispersing preformed microbial biofilm of Staphylococcus epidermidis, Staphylococcus aureus, Streptococcus pyogenes and Pseudomonas aeruginosa and the yeast Candida albicans, all involved in wound infections. Moreover, the cytotoxicity of the compounds was determined in human dermal fibroblast and keratinocytes. In closing, we tested their direct antioxidant activity.
\end{abstract}

Results: Diselenides showed different antimicrobial activity, depending on the microorganism. All diselenides demonstrated a good antibiofilm activity against $S$. aureus and S. epidermidis, the compounds camphor diselenide, bis[ethyl-N-(2'-selenobenzoyl) glycinate] and bis[2'-seleno- $\mathrm{N}$-(1-methyl-2-phenylethyl) benzamide] were active against $\mathrm{S}$. pyogenes and C. albicans biofilm while only diselenides 2,2'-diselenidyldibenzoic acid and bis[ethyl- $\mathrm{N}$-(2'-selenobenzoyl) glycinate] were effective against $P$. aeruginosa. Moreover, the compounds bis[ethyl-N-(2'-selenobenzoyl) glycinate] and bis[2'-seleno-N-(1-methyl-2-phenylethyl) benzamide] showed an antioxidant activity at concentrations lower than the $50 \%$ of cytotoxic concentration.

Conclusions: Because microbial biofilms are implicated in chronic infection of wounds and treatment failure, the combination of antimicrobial activity and potential radical scavenging effects may contribute to the improvement of wound healing. Therefore, this study suggests that bis[ethylN-(2'-selenobenzoyl) glycinate] and bis[2'-seleno- $\mathrm{N}$-(1-methyl-2-phenylethyl) benzamide] are promising compounds to be used in preventing and treating microbial wound infections.

\section{Background}

Common etiologic agents of wound infection are Staphylococcus and Streptococcus species, P. aeruginosa and Enterococcus species [1]. Both acute and chronic wounds are sensitive to bacterial infection. Obesity is increasing worldwide; it is often associated with diabetes and complications such as chronic venous leg ulcers and diabetic foot ulcers. The prevalence of diabetes mellitus is estimated to be more than 371 million people worldwide and the number of diabetic patients is increasing

\footnotetext{
* Correspondence: donatella.pietrella@unipg.it

${ }^{1}$ Department of Pharmaceutical Sciences, University of Perugia, Via del

Giochetto, 06122 Perugia, Italy

Full list of author information is available at the end of the article
}

everywhere [2]. Moreover, pressure ulcers, localized injuries of the skin usually in proximity of bony prominences, are a serious problem for all bed-bound and chair-bound patients [3]. Wound infections may also occur in burn victims [4], patients with traumatic wounds [5], and patients with surgical wounds [6]. The wound environment facilitates the development of microbial communities often associated in biofilms. Biofilms are microbial sessile communities in which microorganisms live attached either to abiotic or biotic substratum or to each other, in a matrix composed of proteins, lipids and polysaccharides, where they are more resistant to antimicrobial drugs and immune system responses with respect to the planktonic form [7]. 
Biofilms are found on the surface of the skin and a considerable amount of evidence suggests their involvement in the delay of wound healing and in the chronic inflammation process [8]. The prevention of biofilm formation is the goal of wound treatment because the standard protocols based on topical and systemic administration are often unable to remove biofilms. In fact, a regular debridement of chronic wounds is the main tool for maintaining a healthy wound bed [9].

Selenium (Se), in the form of selenoproteins or small organoselenium derivatives, is involved in numerous redox equilibrium and redox processes in living systems [10-12] and it is known to catalyze the formation of superoxide radicals which are able to inhibit the attachment of microorganisms to the solid surface [13]. Many studies have demonstrated the antimicrobial activity of different organoselenium compounds [14]. Diselenides have been studied for their antimicrobial activity; diphenyl diselenide and 2,2'-dithienyl diselenide have shown antibacterial and antifungal acivities [15, 16], moreover, selenocyanate and diselenides have been considered as a new class of antileishmanial compounds [17]. Finally, alkyl and aryl diselenides have shown microbial and antiviral activities [18].

In this study, we analyzed the ability of a panel of differently substituted diselenides whose characteristics influence the formation and dispersal of microbial biofilm of $S$. epidermidis, S. aureus, S. pyogenes, P. aeruginosa and the yeast $C$. albicans in different ways. These microorganisms are all involved in wound infections and frequently display drug-resistance, becoming a serious obstacle in acute and chronic wound treatment. Moreover, we tested the cytotoxicity of diselenides in human fibroblasts and keratinocytes and their radical scavenging activity.

\section{Methods}

\section{Diselenides}

All the diselenides used in the study are summarized in Table 1. Diphenyl diselenides (9) is commercially available by Sigma Aldrich; all the other compounds were synthesized with procedures reported in literature starting from antranilic acid $\left(10,10_{\mathrm{d}}, 10_{\mathrm{e}}\right)$ [19], the nicotinic acid $\left(10_{\mathrm{c}}\right)$ [20] and camphor (11) [21]. All compounds were dissolved in methanol and stock solutions, at a concentration of $10 \mathrm{~g} / \mathrm{L}$; they were stored in the dark at $-20{ }^{\circ} \mathrm{C}$.

\section{Microbial strains and growth conditions}

The microbial strains used in this study were the four Gram-positive bacteria Staphylococcus aureus (ATCC 29213), Staphylococcus epidermidis (ATCC 35984), Streptococcus pyogenes (ATCC20565), Streptococcus pneumoniae (ATCC 20566), the Gram-negative Pseudomonas aeruginosa (ATCC 15692) and the yeast Candida albicans (SC5314). The bacterial cultures were maintained in tryptic soy agar (TSA). The day before the test, one colony was inoculated in tryptic soy broth (TSB) and incubated for $24 \mathrm{~h}$ at $37{ }^{\circ} \mathrm{C}$. Candida cells from stock cultures in Sabouraud agar with $50 \mu \mathrm{g} / \mathrm{ml}$ chloramphenicol were grown in Sabouraud broth at $37{ }^{\circ} \mathrm{C}$ for $24 \mathrm{~h}$. Microbial cells were harvested by centrifugation, washed, counted by spectrophotometric analysis and resuspended to the desired concentration in the appropriate culture medium.

Table 1 Diselenides used in the study

Bis[ethyl N-(2'-selenobenzoyl)glycinate]


Determination of minimum inhibitory concentration (MIC) MICs against microbial strains were determined by broth microdilution using two-fold serial dilutions in Muller Hinton Broth for bacteria and RPMI 1640/MOPS for $C$. albicans as described by the Clinical and Laboratory Standards Institute (CLSI) method. The test was carried out in 96-well U-bottom microdilution plates. Microbial inocula were prepared by subculturing bacteria into Muller Hinton Broth (MHB) and Candida cells in Sabouraud Broth at $37{ }^{\circ} \mathrm{C}$ for $18 \mathrm{~h}$ and then diluted to approximately $10^{5}-$ $10^{6} \mathrm{CFU} / \mathrm{ml}$ in MHB or RPMI/MOPS. One hundred $\mu \mathrm{l}$ of test compounds were diluted 1:2 in appropriate medium and placed in a 96-well tissue culture plate. The initial concentrations of the compounds used was $250 \mathrm{mg} / \mathrm{L}$. One hundred $\mu \mathrm{l}$ aliquots of test microorganisms were added to each well. Microplates were then incubated at $37{ }^{\circ} \mathrm{C}$ for $24 \mathrm{~h}$. Each experiment was repeated at least three times. As positive growth control, wells inoculated with microorganisms in the absence of the tested compound were carried out. MIC value was defined as the lowest concentration of compound that inhibits microbial growth. The positive control for Gram-positive and Gram-negative bacteria was gentamicin, and fluconazole for C. albicans.

\section{Growth curve inhibition}

The antimicrobial activity of promising compounds against Gram-positive bacteria was investigated on the basis of MIC values (2xMIC, 1xMIC, $0.2 x M I C)$. Tests were carried out in a 96 well culture plate. Two hundreds $\mu \mathrm{l}$ of microbial suspensions in MHB $\left(10^{5}\right.$ cells $\left./ \mathrm{ml}\right)$ were incubated at $37{ }^{\circ} \mathrm{C}$ in a microplate reader (Infinite 200 pro, TECAN). From time 0 , the absorbance $(600 \mathrm{~nm})$ of the culture was evaluated every $30 \mathrm{~min}$ for a total of $18 \mathrm{~h}$. Results are presented as the mean of absorbance. Each analysis was performed in triplicate.

\section{Effect of diselenides on biofilm formation}

The in vitro static biofilm assay was performed using a 96-well microtiter plate, as previously described, with some modification [22]. Bacteria were grown in TSB overnight. To cultivate biofilms, the overnight cultures of tested microorganisms were diluted 1:100 in fifteen $\mathrm{ml}$ of growth medium (TSB supplemented with $2 \%$ sucrose) in the presence or absence of the different diselenides tested at the concentrations indicated. The positive control for Gram-positive and Gram-negative bacteria was gentamicin and fluconazole for $C$. albicans. Cultures were incubated at $37{ }^{\circ} \mathrm{C}$ for $24 \mathrm{~h}$ in static conditions. After incubation, the biofilm that had developed in each well was washed twice with $200 \mu \mathrm{L}$ of distilled water and then dried for $45 \mathrm{~min}$. One hundred $\mu \mathrm{L}$ of $0.4 \%$ crystal violet were added to each well for 30-45 min. After this procedure, the wells were washed four times with distilled water and immediately discolored with $200 \mu \mathrm{L}$ of $95 \%$ ethanol.
After $45 \mathrm{~min}, 100 \mu \mathrm{L}$ of discolored solution was transferred to a well of a new plate and the crystal violet measured at $570 \mathrm{~nm}$ in a microplate reader (Tecan). The amount of biofilm formed was measured comparing the absorbance values of the compound-treated wells versus untreated control wells. Biofilm formation bioassays were performed in triplicate in at least three individual experiments for each concentration.

\section{Effect of diselenides on biofilm dispersion}

Biofilms were grown on the inside surface of a 96-well microtiter plate. Biofilms grown, as described above, were then treated with three different concentrations of diselenides as dispersion inducer or just the diluent, at the same concentrations used to dilute diselenides as a control, and incubated at $37{ }^{\circ} \mathrm{C}$ for a further $24 \mathrm{~h}$. The positive control for Gram-positive and Gram-negative bacteria was gentamicin, and fluconazole for C. albicans.

Afterward, the biofilm mass was quantified by crystal violet assay. Biofilm dispersal bioassays were performed in triplicate in at least three individual experiments for each concentration.

\section{Antioxidant activity}

The effect of antioxidant compounds on DPPH radical has been detected by spectrophotometer analysis. The reduction of the radical by hydrogen atom transfer from a hydrogen donor (antioxidant) with the formation of the hydrazine DPPH-H causes a change in the color of the solution from violet to pale yellow [23, 24]. The percentage of DPPH radical scavenging ratio of each diselenides was assayed by di(phenyl)-(2,4,6-trinitrophenyl) iminoazanium (DPPH) assay as previously described [25]. DPPH is a stable free-radical molecule at room temperature. In the presence of antioxidant molecules, which can donate hydrogen, DPPH is reduced giving a variation of colour evaluable by spectrophotometry. The reaction mixture consisted of a $100 \mu \mathrm{l}$ of sample and $100 \mu \mathrm{l}$ of DPPH radical solution in ethanol $(50 \mathrm{mg} / \mathrm{L})$. The change in colour (from deep violet to light yellow) of DPPH was determined at $517 \mathrm{~nm}$ after $30 \mathrm{~min}$ of reaction using a microplate reader (Tecan). The mixture of ethanol and sample was used as blank. The control solution was prepared by mixing ethanol and DPPH radical solution. Ascorbic acid was used as a positive control. The percentage of DPPH radical scavenging ratio [26] was calculated according the following formula:

$$
\begin{aligned}
& \% \text { DPPH radical scavenging ratio } \\
& =[1-(\text { Abs sample-Abs blank }) / \text { Abs control }] \times 100 \text {. }
\end{aligned}
$$

\section{Cell viability assay}

Cytotoxicity was tested by the determination of the cell ATP level by ViaLight ${ }^{\oplus}$ Plus Kit (Lonza). This method is 
based upon the bioluminescent measurement of ATP that is present in all metabolically active cells. The bioluminescent method utilizes an enzyme, luciferase, which catalyzes the formation of light from ATP and luciferin. The emitted light intensity is linearly related to the ATP concentration and is measured using a luminometer. All diselenides were tested on a human cervix adenocarcinoma epithelial HeLa cell line (HeLa), human dermis fibroblast $(\mathrm{HuDe})$ and human skin keratinocytes (NCTC2544) cells, which were grown in RPMI 1640 supplemented with $10 \%$ heat-inactivated foetal calf serum, 10,000 units penicillin and $10 \mu \mathrm{g}$ streptomycin/ $\mathrm{ml}$ overnight to confluence. Monolayer cells were treated for $24 \mathrm{~h}$ at $37{ }^{\circ} \mathrm{C}$ with scalar concentrations of tested compounds $(0,0.22,0.45,0.9,1.8,3.9,7.8,15.6,31.25$, $62.5,125,250 \mathrm{mg} / \mathrm{L})$. After incubation, the plates were left at room temperature to cool for $10 \mathrm{~min}$ and then the Cell Lysis Reagent was added to each well to extract ATP form the cells. Next, after $10 \mathrm{~min}$, the AMR Plus (ATP Monitoring Reagent Plus) was added and after 2 more minutes the luminescence was read using a microplate luminometer (TECAN). Results are expressed as $\mathrm{CC}_{50}$. The $50 \%$ cytotoxic concentration $\left(\mathrm{CC}_{50}\right)$ was defined as the concentration required to reduce the live cell number by $50 \%$, compared to the untreated controls.

\section{Statistical analysis}

All experiments were performed in triplicate in at least three different experiments. Data were expressed as mean \pm SD. Differences between diselenide-treated biofilm and untreated biofilm were compared using the Student's t-test (two-tailed). " $P$-values of $<0.05$ were considered significant.

\section{Results}

\section{Antimicrobial activity of diselenides}

The screening of diselenides as antimicrobial drugs versus different microorganisms is shown in Table 2. The results indicated that MIC of compounds 9 and 10 showed a moderate antimicrobial activity against $S$. epidermidis, $S$. pyogenes and $C$. albicans; whereas compounds $10_{\mathrm{d}}$ and $10_{\mathrm{e}}$ demonstrated considerable antibacterial activity versus S. epidermidis and S. pyogenes.

The kinetics of microbial growth were investigated to identify the right concentration of compounds to use in the antibiofilm test to keep out direct antimicrobial properties. The inhibitory effects of diselenides on the growth of S. epidermidis, S. pyogenes, $P$. aeruginosa and C. albicans are reported in Fig. 1. At the concentration of $2 x M I C$ and $1 \times$ MIC, all the compounds inhibited the growth of all microorganisms (data non shown), while at $0.2 x M I C$ for bacteria and $0.5 x M I C$ for $C$. albicans the growth curves observed were not significantly different to those obtained for untreated bacterial cultures,
Table 2 Minimal Inhibitory Concentration (MIC) of diselenides against different microorganisms

\begin{tabular}{lccccccc}
\hline MIC (mg/L) & 9 & 10 & 11 & $10 \mathrm{c}$ & $10 \mathrm{~d}$ & $10 \mathrm{e}$ & $\begin{array}{c}\text { Positive } \\
\text { control }^{\text {a }}\end{array}$ \\
\hline $\begin{array}{l}\text { Staphylococcus } \\
\text { aureus }\end{array}$ & $>250$ & 125 & 250 & $>250$ & $>250$ & 31.25 & 7.8 \\
$\begin{array}{l}\text { Staphylococcus } \\
\text { epidermidis }\end{array}$ & 15.62 & 3.9 & $>250$ & $>250$ & 7.8 & 7.8 & 0.18 \\
$\begin{array}{l}\text { Streptococcus } \\
\text { pyogenes }\end{array}$ & 15.62 & 7.8 & 31.25 & $>250$ & 15.62 & 31.25 & 2.19 \\
$\begin{array}{l}\text { Streptococcus } \\
\text { pneumoniae }\end{array}$ & $>250$ & 125 & $>250$ & 250 & $>250$ & $>250$ & 0.45 \\
$\begin{array}{l}\text { Pseudomonas } \\
\text { aeruginosa }\end{array}$ & $>250$ & $>250$ & $>250$ & $>250$ & 250 & $>250$ & 1.5 \\
Candida albicans & 31.25 & 62.5 & 125 & $>250$ & $>250$ & $>250$ & 0.25 \\
\hline
\end{tabular}

MIC was evaluated by standardized CLSI methods

aThe positive control for Gram-positive and Gram-negative bacteria was gentamicin and Fluconazole for Candida albicans

suggesting that diselenides did not affect microbial division at the concentrations tested.

\section{Antibiofilm activity}

To analyze in depth the antimicrobial properties of diselenides, we examined the ability of $S$. aureus, $S$. epidermidis, S. pyogenes, $P$. aeruginosa and C. albicans to form biofilm in the absence or presence of organoselenium compounds. Biofilm formation was measured by determining the mass of biofilm using crystal violet staining. Biofilms were grown in static conditions in the presence of diselenides at concentrations lower than MIC. In particular, we used a concentration of $0.2 \times$ MIC for the bacterial strains tested and $0.5 \times$ MIC for C. albicans, which resulted ineffective on microbial growth (Fig. 1). For diselenides with a $\mathrm{MIC} \geq 250 \mathrm{mg} / \mathrm{L}$, we used the concentration of $50 \mathrm{mg} / \mathrm{L}$. All diselenides showed a good antibiofilm activity against the Gram-positive bacteria $S$. aureus and S. epidermidis, while diselenides $11,10_{\mathrm{d}}$ and $10_{\mathrm{e}}$ were effective against $S$. pyogenes. Diselenides resulted less active against $P$. aeruginosa, in fact only compound 10 and 10d reduced anti-biofilm activity by $20 \%$ and $40 \%$ respectively. Finally, diselenides $9,11,10_{\mathrm{d}}$ and $10_{\mathrm{e}}$ showed anti-biofilm activity against the yeast $C$. albicans (Fig. 2).

In parallel experiments, the ability of diselenides to disperse preformed biofilm was assayed against Grampositive bacteria and the yeast C. albicans. Different concentrations of diselenides corresponding to the $1 \times$ MIC, $0.5 \times$ MIC and $0.1 \times$ MIC were added on preformed biofilm and their effect on dispersal was determined after $24 \mathrm{~h}$ of incubation. For diselenides with a $\mathrm{MIC} \geq 250 \mathrm{mg} / \mathrm{L}$ we tested the concentrations 250, 125 and $25 \mathrm{mg} / \mathrm{L}$. The results in Fig. 3, showed that diselenides $10_{\mathrm{d}}$ and $10_{\mathrm{e}}$ were able to reduce the biofilm mass of $S$. epidermidis, compound $10_{\mathrm{d}}$ was able to reduce biofilm at all concentrations tested; of note is that this 


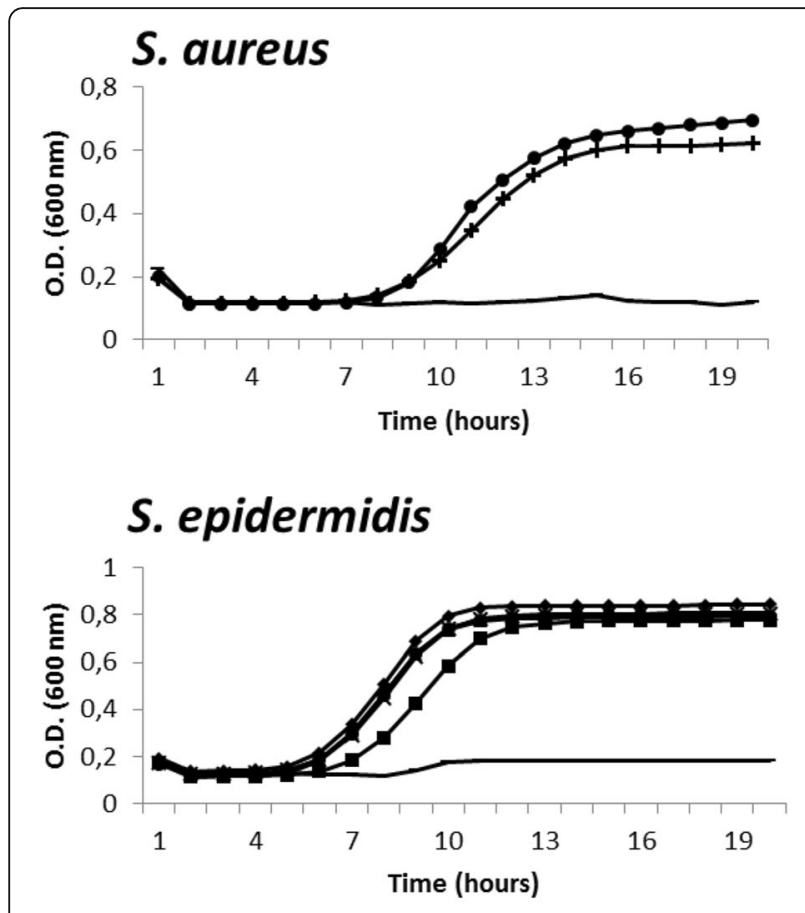

\section{S. pyogenes}
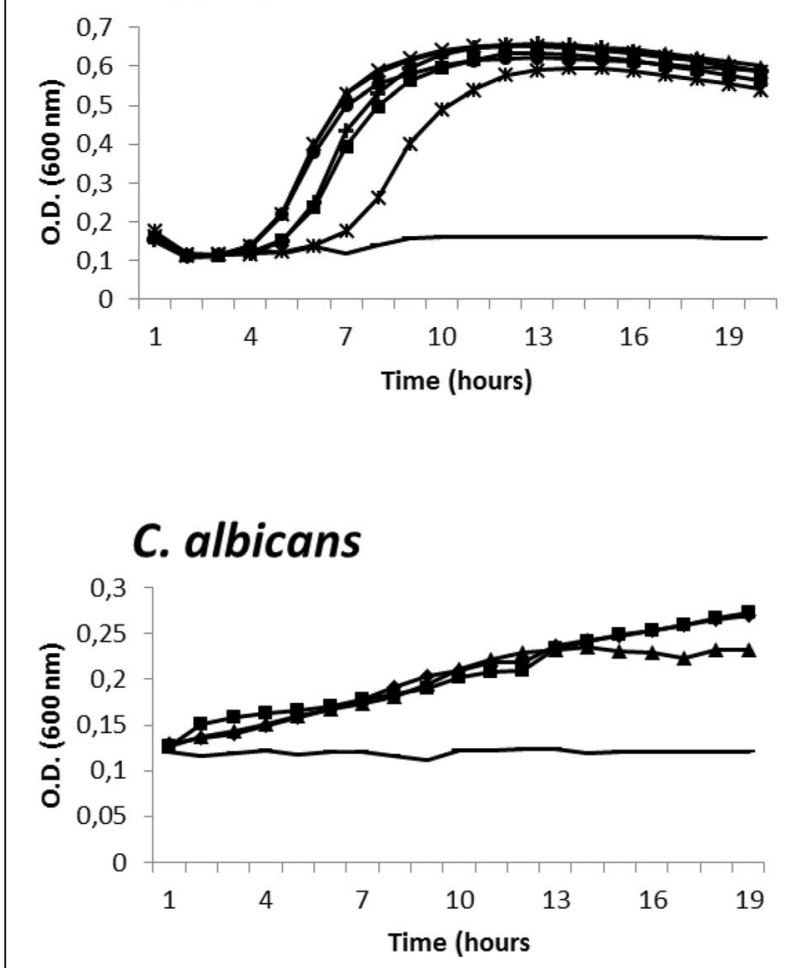

Fig. 1 Growth curve of S. epidermidis, S. pyogenes, P. aeruginosa and $C$. albicans in the presence of diselenides. Concentrations of diselenides $0.2 \mathrm{xMIC}$ or $0.5 \mathrm{xMIC}$ were tested for bacteria or fungus respectively. The positive control for Gram-positive and Gram-negative bacteria was gentamicin, and fluconazole for Candida albicans (untreated microorganisms: filled circles, 9: filled squares, 10: filled triangles, 11:*, 10: filled rhombuses, 10d: X, 10: + , positive control -).

Data are expressed as a mean of six replicates from two

independent experiments

compound was able to reduce the biofilm mass at one tenth of the MIC confirming that the antibiofilm effect is not due to a direct killing effect; instead compound $10_{\mathrm{e}}$ was active in the amount of $1 \mathrm{xMIC}$ and one half of MIC. Biofilm compounds 10 and $10_{\mathrm{d}}$ showed inhibitory activity against $S$. aureus at all doses tested, while diselenides 9 and $10_{\mathrm{e}}$ were active up to $0.5 \mathrm{MIC}$. Diselenides $9,10,1110_{\mathrm{d}}$ and $10_{\mathrm{e}}$ were able to decrease the preformed biofilm S. pyogenes at concentrations of 1 and $0.5 \times$ MIC. Finally, C. albicans preformed biofilm was dispersed by compounds $9,11,10_{\mathrm{d}}$ and $10_{\mathrm{e}}$ at all concentrations tested (Fig. 3). Up to this point, compound $10_{\mathrm{d}}$ was the most active in this series of diselenides.

\section{Antioxidant activity}

Non-healing wounds in humans have shown high oxidative and nitrosative stress [27-29]. Exacerbation of oxidative stress and biofilm-forming bacteria are critical for the initiation of chronicity [27]. In the last few decades, the biological antioxidant property of new synthetic organic selenium compounds has been reported [30-35]. The antioxidant mechanism of action of organoselenium compounds depends on the cellular environment. These agents do not change the redox balance themselves, but their activities depend on the cellular redox state in which they are placed. Mounting evidence suggests that regular uptake of antioxidants is required to scavenge ROS (Radical Oxygen Species) and RNS (Radical Nitrogen Species) [36, 37].

In order to develop strategies to reduce redox stress and inhibit biofilm formation to restore wound tissue, we tested the antioxidant activity of diselenides at three different concentrations (100-50-10-1-0.1 $\mathrm{mg} / \mathrm{L})$ by $\mathrm{DPPH}$ assay. As negative control, the diluent used in preparing stock solution of diselenides was used; methanol was added to the sample and its antioxidant activity was determined. The results shown in Fig. 4 prove that compounds 9, 10, 11 and $10_{\mathrm{c}}$ had no antioxidant activity at concentrations of $0.1,1$ and $10 \mathrm{mg} / \mathrm{L}$ and a weak activity at 50 and $100 \mathrm{mg} / \mathrm{L}$. Furthermore, diselenides $10_{\mathrm{d}}$ and $10_{\mathrm{e}}$ exhibited a moderate dose scavenging activity at $10 \mathrm{mg} / \mathrm{L}$ and a very good antioxidant property at 50 and $100 \mathrm{mg} / \mathrm{L}$ as compared to that observed with the positive control ascorbic acid. 

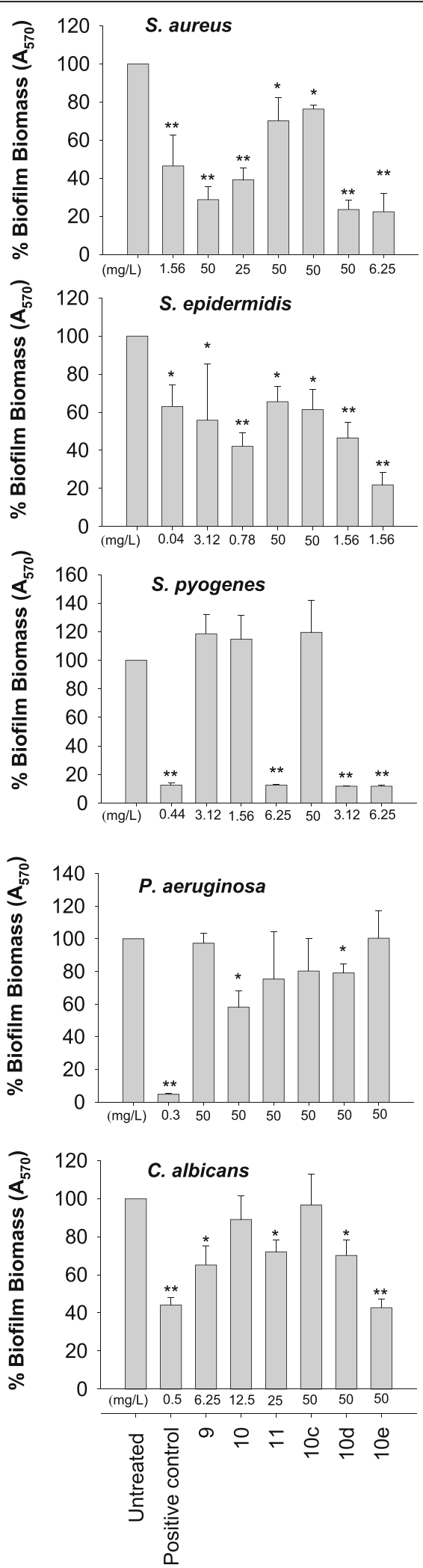

Fig. 2 The effect of diselenides on biofilm formation. S. aureus, S. epidermidis, S. pyogenes, P. aeruginosa, and Candida albicans were inoculated into a 96-well plate containing diselenides and incubated for $24 \mathrm{~h}$. The concentration of the different diselenides used for each microorganism is indicated under the X-axis of the corresponding histogram. Biofilm biomass was quantified by crystal violet assay (absorbance $570 \mathrm{~nm}$ ). Data represent the mean \pm SD of 2 or more independent experiments performed in triplicate. ${ }^{*} P<0.05$, ${ }^{* *} P<0.01$ (treated microorganisms versus untreated cells)

\section{Biocompatibility of Diselenides}

For tissue engineering materials or drug carrier application, diselenides must be non-toxic and biocompatible. HeLa human epithelial cells, HuDe human dermal fibroblast cells and NCTC2544 human keratinocyte cells were exposed to scalar concentrations of diselenides before ATP level measurement. The $\mathrm{CC}_{50}$ obtained for all diselenides tested is reported in Table 3. Diselenides exhibited different cytotoxicity toward different cell lines. Compounds $11,10_{\mathrm{d}}$ and $10_{\mathrm{e}}$ were highly toxic against HeLa cells, while diselenide $10_{c}$ showed mild toxicity and compounds 9 and 10 had low toxicity. Human fibroblast $\mathrm{HuDe}$ showed a slight reduction in vitality in the presence of compounds $10,10_{\mathrm{d}}$ and $10_{\mathrm{e}}$, while diselenides $9,10_{c}$ were mildly toxic and compound 11 showed a strong toxicity. Finally, for human keratinocytes NCTC2544, the $\mathrm{CC}_{50}$ of compounds $10_{\mathrm{c}}$ and $10_{\mathrm{e}}$ was $\geq$ $250 \mathrm{mg} / \mathrm{L}$; diselenides 10 , and $10_{\mathrm{d}}$ showed moderate toxicity while compounds 9 and 11 were toxic.

\section{Discussion}

Given the role that pathogenic biofilms play in impairing the healing of chronic wounds, preventing biofilm formation is fundamental for faster and more effective treatment. When the biofilm is well established, microorganisms inside the matrix will exhibit resistance to killing by the host immune system and antimicrobials. In the past two decades a variety of organoselenium compounds have been tested against bacteria, fungi, algae and viruses. Most of them have shown a good activity with respect to the antimicrobial drugs in current use [14]. In particular, organoselenium coating on cellulose was able to inhibit $P$. aeruginosa and $S$. aureus biofilm formation [38, 39]. The antifungal property of biphelyl diselenide $(\mathrm{PhSe})_{2}$ against different species of Candida has been reported by Loreto ES et al. [16]. The values for $C$. albicans reported in their study are similar to those obtained in our experimental conditions.

The antibiofilm activity of other organoselenium compounds against $P$. aeruginosa [36] and $S$. aureus has been tested in in vivo and in vitro studies [36, 37]. We tested six diselenides for their activity against preformed biofilms as well during biofilm formation. All compounds were able to reduce the biofilm formation of Gram-positive 


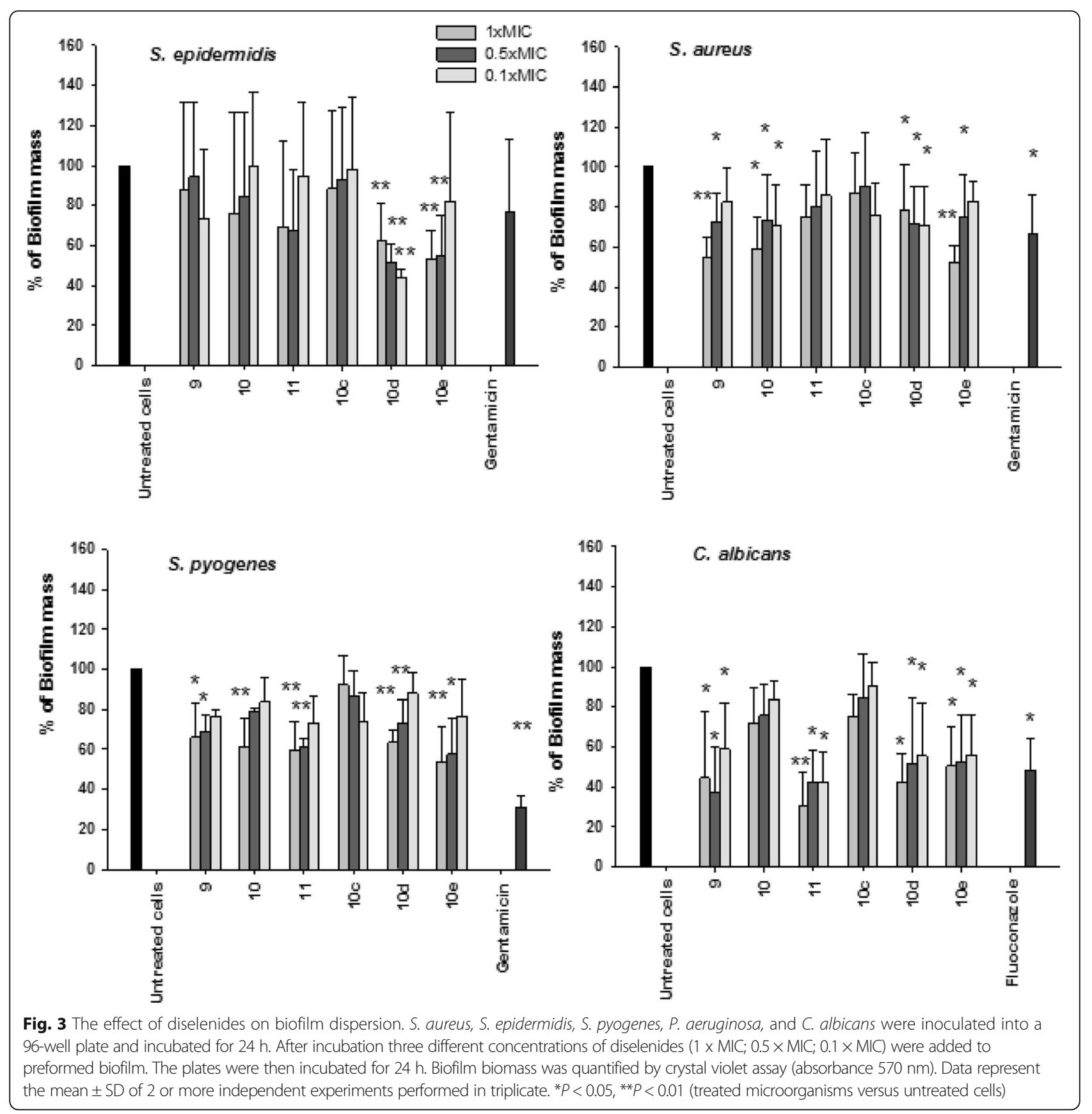

Staphylococci. Diselenides $11,10_{\mathrm{d}}$ and $10_{\mathrm{e}}$ inhibited the formation of $S$. pyogenes biofilm; while, only compounds 10 and $10_{\mathrm{d}}$ were active against the Gram-negative $P$. aeruginosa. This effect is probably due to the different structures of the microbial cell walls. Dispersal of the biofilm test showed that $S$. epidermidis biofilm is dispersed by diselenides $10_{\mathrm{c}}$ and $10_{\mathrm{d}}$, while $S$. aureus biofilm is partially reduced by compounds $9,1010_{\mathrm{d}}$ and $10_{\mathrm{e}}$; dispersal biofilm of $S$. pyogenes has been observed in the presence of all compounds except $10_{\mathrm{c}}$. Compounds $9,10,10_{\mathrm{d}}$ and $10_{\mathrm{e}}$ were able to inhibit and to disperse the biofilm of $C$. albicans. The overall results evidenced that diselenides $10_{\mathrm{d}}$ and $10_{\mathrm{e}}$ showed the best antibiofilm activity both in biofilm formation and dispersion. The antimicrobial activity of 2,2'-dithienyl diselenide against bacteria and C. albicans has been recently reported; the mechanism of action suggested was the pro-oxidant activity [15]. However, the anti-oxidant activity of diselenides has been demonstrated [23]. This apparent incongruity is consistent with the structures of diselenides $10_{\mathrm{d}}$ and $10_{\mathrm{e}}$; in fact the amide group, by a nonbonding interaction, enhances the electrophilicity of the selenium atom, by activating the 


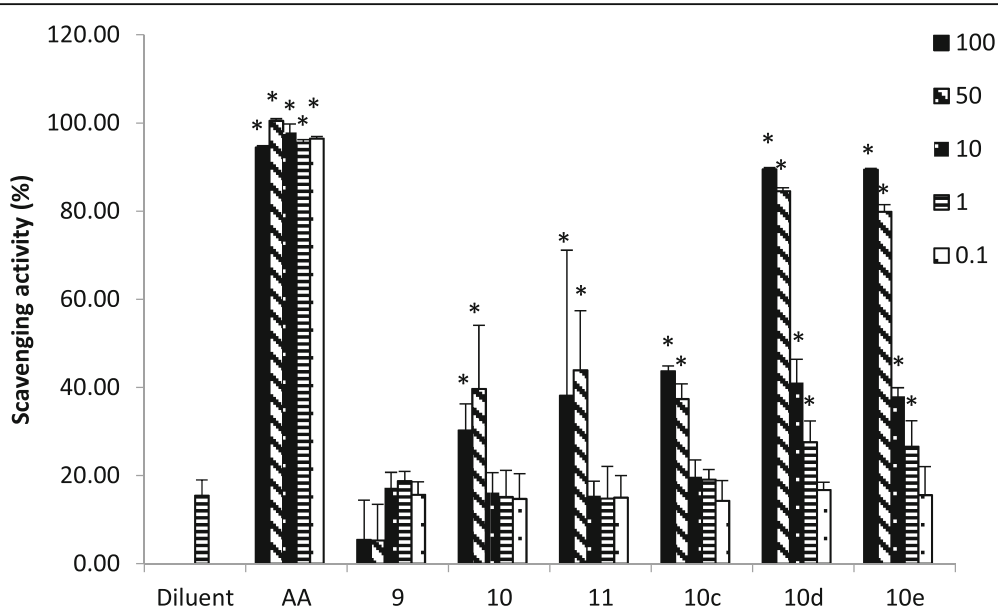

Fig. 4 Antioxidant activity of diselenides. Antioxidant activity was determined by DPPH reduction; diselenide activity was determined and compared to the standard ascorbic acid (AA). Results are expressed as DPPH scavenging activity. Data represent the mean \pm SD of 2 or more independent experiments performed in triplicate. Differences between antioxidant activity of diselenides and diluent were compared using the Student's t-test (two-tailed). ${ }^{*} P<0.05$, (diselenides effect versus diluent effect)

oxidation of the dichalcogenide bond. This confers radical scavenger properties to the structure but, at the same time, the oxidative cleavage of the Se-Se bond leads to the formation of strongly oxidant intermediates (e.g. selenenic and seleninic species). If not readily reduced by a glutathione mediated reaction (like in the GPx catalytic cycle), such intermediates can be responsible for the pro-oxidant activity.

The antioxidant activity of new selenide compounds has been reported; monoselenides showed a weaker effect compared to diselenides [39-41]. Novel nitrogencontaining diselenides can act against oxidative stress through a glutathione peroxidase-like activity [19]. As $S$. aureus, S. epidermidis and S. pyogenes are the most common isolates among wound infections [8], we can assume that diselenides have a potential for development as therapeutic antimicrobials for wound infections. Moreover, diselenides affected cell vitality according to the cell line used; fibroblast $\mathrm{HuDe}$ cells resulted more resistant than human keratinocytes to compounds $9,10,10_{\mathrm{d}}$ and $10_{\mathrm{e}}$, while NCTC2544 cells are less sensitive to diselenide $10_{\mathrm{c}}$. The different cytotoxic activity is likely due to the intrinsic

Table 3 Cytotoxicity of diselenides against Hela, HDF and NCTC2544 cell lines

\begin{tabular}{lllllll}
\hline $\mathrm{CC}_{50}(\mathrm{mg} / \mathrm{L})$ & \multicolumn{1}{l}{1} & \multicolumn{1}{l}{10} & \multicolumn{1}{c}{11} & \multicolumn{1}{c}{$10_{\mathrm{c}}$} & \multicolumn{1}{c}{$10_{\mathrm{d}}$} & $10_{\mathrm{e}}$ \\
\hline Hela & 123.69 & 113.69 & 10.92 & 32.16 & 19.25 & 9.71 \\
HDF & 55.02 & 135.86 & 8.36 & 35.29 & 112.93 & $>250$ \\
NCTC2544 & 14.62 & 44.61 & 18.45 & 250.00 & 23.84 & $>250$ \\
\hline
\end{tabular}

Cytotoxicity was tested by the determination of the cell ATP level by a bioluminescent method after $24 \mathrm{~h}$ of incubation. $\mathrm{CC}_{50}$ is the concentration required to reduce the live cell number by $50 \%$ compared to the untreated controls. The $\mathrm{CC}_{50}$ values are reported as the means from two independent experiments performed in duplicate differences among cell lines and multiple factors such as cell permeability and macromolecular target binding.

\section{Conclusions}

In conclusions, considering that compound $10_{\mathrm{e}}$ was the most biocompatible against fibroblast and keratinocytes, the antioxidant activity of compounds $10_{\mathrm{d}}$ and $10_{\mathrm{e}}$ and the antibiofilm properties of compounds $10_{\mathrm{d}}$ and $10_{\mathrm{e}}$ against S. aureus, S. epidermidis, S. pyogenes and C. albicans, diselenides $10_{\mathrm{d}}$ and $10_{\mathrm{e}}$ could be very good candidates for the development of new therapeutic applications for acute wound infections as well as chronic skin diseases such as diabetic foot ulcers and venous stasis ulcers may be possible.

\section{Abbreviations}

AA: Ascorbic acid; AMR: ATP Monitoring Reagent; ATP: Adenosine triphosphate; $\mathrm{CC}_{50}$ : 50 \% cytotoxic concentration; CLSI: Clinical and Laboratory Standards Institute; DPPH: di(phenyl)-(2,4,6-trinitrophenyl) iminoazanium; GPx: Glutathione peroxidase; HeLa: HeLa cell line; HuDe: human dermis fibroblast; MHB: Muller Hinton Broth; MIC: Minimum inhibitory concentration; MOPS: 3-(N-morpholino)propanesulfonic acid; NCTC2544: Human skin keratinocytes; RNS: Radical nitrogen species; ROS: Radical oxygen species; RPMI: Roswell Park Memorial Institute; SD: Standard deviation; TSA: Tryptic soy agar; TSB: Tryptic soy broth

\section{Acknowledgments}

This manuscript is part of the educational activity of the multi-disciplinary group "SeS redox and catalysis".

\section{Funding}

This work was supported by Consorzio CINMPIS, Bari (Consorzio Interuniversitario Nazionale di Metodologie e Processi Innovativi di Sintesi), Regione Umbria progetto "POR Umbria 2007-2013" and CAPES (7569-13-0) and a grant from the University of Perugia (Ricerca di base 2015).

Availability of data and material

The data and material supporting the conclusions of this work are included within the article as additional supporting files. 


\section{Authors' contributions}

$\mathrm{DP}, \mathrm{RP}$ and CS participated in designing methodology, analysing results and writing the manuscript. DP LS, VN and ALB synthetized or provided compounds. MP and SDM participated in carrying out the work. All authors read and approved the final manuscript.

\section{Competing interests}

The authors declare that they have no competing interests.

\section{Consent for publication}

Not applicable.

\section{Ethics approval and consent to participate}

Not applicable.

\section{Author details}

'Department of Pharmaceutical Sciences, University of Perugia, Via del Giochetto, 06122 Perugia, Italy. ${ }^{2}$ Laboratorio de Sintese de Substancias de Selenio Bioativas, Centro de Ciencias Fisicas e Matematicas, Departamento de Quimica, Universidade Federal de Santa Catarina, 88040-900 Florianopolis, SC, Brazil.

Received: 24 May 2016 Accepted: 13 September 2016

Published online: 21 September 2016

\section{References}

1. Scales BS, Huffnagle GB. The microbiome in wound repair and tissue fibrosis. J Pathol. 2013;229:323-31.

2. Home P, Mant J, Diaz J, Turner C. Management of type 2 diabetes: summary of updated NICE guidance. BMJ. 2008:336:1306-8.

3. Petzold T, Eberlein-Gonska M, Schmitt J. Which factors predict incident pressure ulcers in hospitalized patients? A prospective cohort study. Br J Dermatol. 2014;170:1285-90.

4. Church D, Elsayed S, Reid O, Winston B, Lindsay R. Burn wound infections. Clin Microbiol Rev. 2006;19:403-34

5. Murray CK. Infectious disease complications of combat-related injuries. Crit Care Med. 2008:36:5358-64.

6. Markogiannakis H, Pachylaki N, Samara E, Kalderi M, Minettou M, Toutouza M, Toutouzas KG, Theodorou D, Katsaragakis S. Infections in a surgical intensive care unit of a university hospital in Greece. Int J Infect Dis. 2009;13: $145-53$.

7. Donlan RM, Costerton JW. Biofilms: survival mechanisms of clinically relevant microorganisms. Clin Microbiol Rev. 2002;15:167-93.

8. Percival SL, Hill KE, Williams DW, Hooper SJ, Thomas DW, Costerton JW. A review of the scientific evidence for biofilms in wounds. Wound Repair Regen. 2012;20:647-57.

9. Wolcott RD, Kennedy JP, Dowd SE. Regular debridement is the main tool for maintaining a healthy wound bed in most chronic wounds. J Wound Care. 2009;18:54-6.

10. Bartolini D, Piroddi M, Tidei C, Giovagnoli S, Pietrella D, Manevich Y, Tew KD, Giustarini D, Rossi R, Townsend DM, Santi C, Galli F. Reaction kinetics and targeting to cellular glutathione $\mathrm{S}$-transferase of the glutathione peroxidase mimetic PhSeZnCl and its D, L-polylactide microparticle formulation. Free Radic Biol Med. 2015;78:56-65.

11. Santi C, Galli F, Piroddi M, Tidei C. Thiols Oxidation for the Evaluation of Gpx-Like Activity. Phosphorus Sulfur Silicon Relat Elem. 2013;188:507-8.

12. Tidei C, Piroddi M, Galli F, Santi C. Oxidation of thiols promoted by PhSeZnCl. Tetrahedron Lett. 2012;53:232-4.

13. Mathews SM, Spallholz JE, Grimson MJ, Dubielzig RR, Gray T, Reid TW. Prevention of bacterial colonization of contact lenses with covalently attached selenium and effects on the rabbit cornea. Cornea. 2006;25:806-14.

14. Pietrella D. Antimicrobial Activity of Organoselenium Compounds. In: Santi C, editor. Organoselenium Chemistry: Between Synthesis and Biochemistry. Sharjah: Bentham Books; 2014. p. 328-44.

15. Pesarico AP, Sartori G, dos Santos CF, Neto JS, Bortolotto V, Santos RC, Nogueira CW, Prigol M. 2,2'-Dithienyl diselenide pro-oxidant activity accounts for antibacterial and antifungal activities. Microbiol Res. 2013;168: 563-8.

16. Loreto ES, Mario DA, Santurio JM, Alves SH, Nogueira CW, Zeni G. In vitro antifungal evaluation and structure-activity relationship of diphenyl diselenide and synthetic analogues. Mycoses. 2011;54:e572-6.
17. Plano D, Baquedano Y, Moreno-Mateos D, Font M, Jiménez-Ruiz A, Palop JA, Sanmartín C. Selenocyanates and diselenides: a new class of potent antileishmanial agents. Eur J Med Chem. 2011;46:3315-23.

18. Wójtowicz H, Chojnacka M, Młochowski J, Palus J, Syper L, Hudecova D, Uher M, Piasecki E, Rybka M. Functionalized alkyl and aryl diselenides as antimicrobial and antiviral agents: synthesis and properties. Farmaco. 2003; 58:1235-42.

19. Nascimento V, Ferreira NL, Canto RF, Schott KL, Waczuk EP, Sancineto L, Santi C, Rocha JB, Braga AL. Synthesis and biological evaluation of new nitrogen-containing diselenides. Eur J Med Chem. 2014;87:131-9.

20. Prabhu CP, Phadnis PP, Wadawale AP, Jayn VK. Synthesis, chracterization, structures and antioxidant activity of nicotinoyl based organoselenium compounds. J Organomet Chem. 2012;713:42-50.

21. Back TG, Dyck B, Parvez M. Unexpected formation of 1,3-diselenetanes from reaction of camphor enolate with selenium. J Chem Soc Chem Comm. 1994;4:515-6.

22. Iwase T, Uehara Y, Shinji H, Tajima A, Seo H, Takada K, Agata T, Mizunoe Y. Staphylococcus epidermidis Esp inhibits Staphylococcus aureus biofilm formation and nasal colonization. Nature. 2010:465:346-9.

23. Luchese C, Nogueira CW. Diphenyl diselenide in its selenol form has dehydroascorbate reductase and glutathione S-transferase-like activity dependent on the glutathione content. J Pharm Pharmacol. 2010;62: $1146-51$.

24. Ancerewicz J, Migliavacca E, Carrupt PA, Testa B, Brée F, Zini R, Tillement JP, Labidalle S, Guyot D, Chauvet-Monges AM, Crevat A, Le Ridant A. Structureproperty relationships of trimetazidine derivatives and model compounds as potential antioxidants. Free Radic Biol Med. 1998;25:113-20.

25. Garcia EJ, Oldoni TL, Alencar SM, Reis A, Loguercio AD, Grande RH. Antioxidant activity by DPPH assay of potential solutions to be applied on bleached teeth. Braz Dent. 2012;23:22-7.

26. Lu CL, Zhu W, Wang M, Xu XJ, Lu CJ. Antioxidant and Anti-Inflammatory Activities of Phenolic-Enriched Extracts of Smilax glabra. Evid Based Complement Alternat Med. 2014;2014:910438.

27. Dhall S, Do D, Garcia M, Wijesinghe DS, Brandon A, Kim J, Sanchez A, Lyubovitsky J, Gallagher S, Nothnagel EA, Chalfant CE, Patel RP, Schiller N, Martins-Green M. A novel model of chronic wounds: importance of redox imbalance and biofilm-forming bacteria for establishment of chronicity. PLoS One. 2014:9:e109848.

28. Wlaschek M, Scharffetter-Kochanek K. Oxidative stress in chronic venous leg ulcers. Wound Repair Regen. 2005;13:452-61.

29. Yang Q, Phillips PL, Sampson EM, Progulske-Fox A, Jin S, Antonelli P, Schultz GS. Development of a novel ex vivo porcine skin explant model for the assessment of mature bacterial biofilms. Wound Repair Regen. 2013; 21:704-14.

30. Mugesh GaS HB. Synthetic organoselenium compounds as antioxidants: glutathione peroxidase activity. Chem Soc Rev. 2000;29:347-57.

31. Müller A, Cadenas E, Graf P, Sies H. A novel biologically active selenoorganic compound-I. Glutathione peroxidase-like activity in vitro and antioxidant capacity of PZ 51 (Ebselen). Biochem Pharmacol. 1984;33: 3235-9

32. Nogueira CW, Zeni G, Rocha JB. Organoselenium and organotellurium compounds: toxicology and pharmacology. Chem Rev. 2004;104:6255-85.

33. Parnham M, Sies H. Ebselen: prospective therapy for cerebral ischaemia. Expert Opin Investig Drugs. 2000;9:607-19.

34. Rosa RM, Roesler R, Braga AL, Saffi J, Henriques JA. Pharmacology and toxicology of diphenyl diselenide in several biological models. Braz J Med Biol Res. 2007:40:1287-304.

35. Sies $\mathrm{H}$. Ebselen, a selenoorganic compound as glutathione peroxidase mimic. Free Radic Biol Med. 1993;14:313-23.

36. Shaaban S, Negm A, Sobh MA, Wessjohann LA. Organoselenocyanates and symmetrical diselenides redox modulators: Design, synthesis and biological evaluation. Eur J Med Chem. 2015;97:190-201.

37. Ibrahim M, Hassan W, Anwar J, Deobald AM, Kamdem JP, Souza DO, Rocha JB. 1-(2-(2-(2-(1-Aminoethyl) phenyl)diselanyl) phenyl) ethanamine: an amino organoselenium compound with interesting antioxidant profile. Toxicol In Vitro. 2014:28:524-30.

38. Tran PL, Hammond AA, Mosley T, Cortez J, Gray T, Colmer-Hamood JA, Shashtri M, Spallholz JE, Hamood AN, Reid TW. Organoselenium coating on cellulose inhibits the formation of biofilms by Pseudomonas aeruginosa and Staphylococcus aureus. Appl Environ Microbiol. 2009;75: 3586-92. 
39. Tran PL, Lowry N, Campbell T, Reid TW, Webster DR, Tobin E, Aslani A, Mosley T, Dertien J, Colmer-Hamood JA, Hamood AN. An organoselenium compound inhibits Staphylococcus aureus biofilms on hemodialysis catheters in vivo. Antimicrob Agents Chemother. 2012:56:972-8.

40. Sharma OP, Bhat TK. DPPH antioxidant assay revisited. Food Chem. 2009; 113:1202-5.

41. Stefanello ST, Prestes AS, Ogunmoyole T, Salman SM, Schwab RS, Brender $C R$, Dornelles $L$, Rocha JB, Soares FA. Evaluation of in vitro antioxidant effect of new mono and diselenides. Toxicol In Vitro. 2013;27:1433-9.

Submit your next manuscript to BioMed Central and we will help you at every step:

- We accept pre-submission inquiries

- Our selector tool helps you to find the most relevant journal

- We provide round the clock customer support

- Convenient online submission

- Thorough peer review

- Inclusion in PubMed and all major indexing services

- Maximum visibility for your research

Submit your manuscript at www.biomedcentral.com/submit 